\section{THE TISSUE-LYMPH CIRCULATION. ${ }^{1}$}

A FTER paying a warm tribute to the memory of his A teacher in physiology, the late Prof. Sharpey, F.R.S., the lecturer proceeded.

I propose to submit to you the results of a study on the circulation of the tissue fluid in man, or, in other words, on the fluid transfers between the blood and the tissues. Apart from its intrinsic physiological interest this subject has important bearings on the practice of medicine.

Some of the conclusions suggested to me by this inquiry

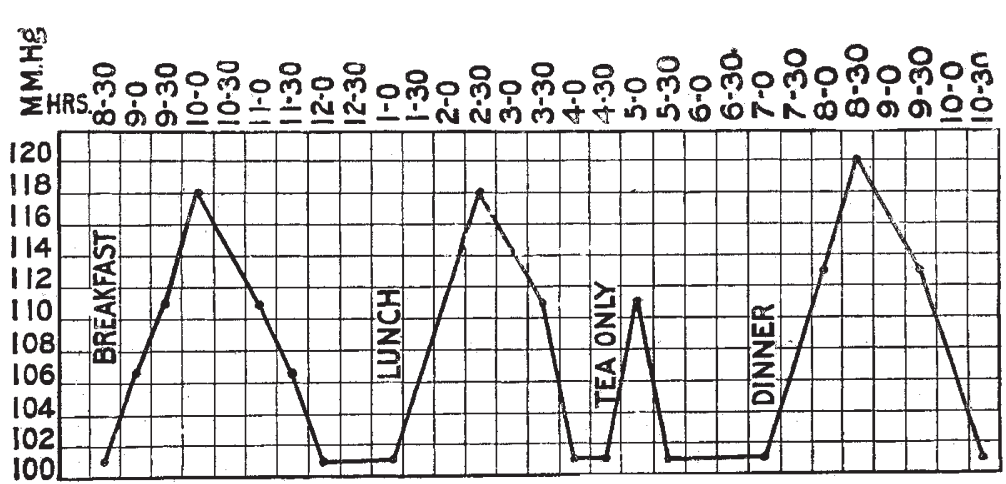

F1G. I.-Chart showing rise of arterial pressure after food.

if both these pressures rise or fall together we may fairly assume that the capillary pressure will also rise or fall. After food the pulse-rate also increases, and in an hour it may have gained from eight to fifteen beats a minute. When the pulse pressure gauge is applied so as to arrest the pulsation of the radial artery (the finger being used as the indicator), the reading becomes cardiometric, and is generally increased in an hour after a meal from $I_{5}$ to 20 millimetres of mercury. Therefore it would seem that digestion very considerably stimulates the heart, augmenting the output and the contractile energy of the ventricle.

The essential aim of the digestive excitation of the circu-

latory system is to raise the capillary blood pressure, and according to my observations this end is attained by the increased activity of the cardiac muscle. But it can likewise be secured by taking with a meal some substance which dilates the arteries and arterioles, and thus lowers the arterial pressure; then the venous pressure is greatly increased, and the capillary pressure must be raised, being between two pressures higher than the normal capillary pressure.

We may therefore infer that we may have a rise in the capillary pressure either with an increase or a decrease of the arterial pressure according as we have cardiac stimulation (as after meals) or vaso-dilation.

Digestive Variations in the Blood.

I have followed three series of alterwere so unexpected that I was naturally led to repeat my observations in every department of it over and over again, and to scrutinise all the facts with more than ordinary diligence. More than 3000 observations have been made in health and disease, but I propose in these lectures to use mainly the physiological material.

\title{
Methods and Apparatus.
}

[Dr. Oliver here described the methods and apparatus employed with certain improvements in the hæmocytometer, hæmoglobinometer, and hæmodynamometer.]

ThE EFFect OF THE Ingestion OF FoOD ON THE TISSUE-LYMPH Circulation.

Elsewhere ${ }^{2}$ I have shown that the ingestion of food initiates an interesting series of variations in the blood and blood pressures which culminates in a prolonged wave-like exudation of tissue-lymph, and that this excitation in the circulatory system recurs with perfect regularity after each meal. Subsequent inquiry has amply confirmed this position.

The digestive variations in the blood pressure.-The ingestion of food invariably raises the arterial blood pressure (Fig. I). In an hour after a meal it rises 15 or even 20 millimetres of mercury, then it begins to fall, and in from two and a half to three and a half hours it becomes stationary until the next meal or until exercise is taken. The curve of the venous pressure rises and falls throughout with that of the

CORPUSCLES

PER CMM PERCEN $3.400 .000(108$

5300.000

5200000

5100000

5000000

4900000

4800000

4700000

\subsection{0}

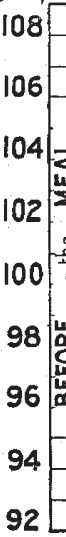

SPECIFIC GRAVITY of BLOOD corpuscles, in the hæmoglobin, and in the specific gravity. As the variations in the chromocytes and in the hæmoglobin are identical, they are taken together.

Digestive variations in the corpuscles and haemoglobin.The finger, having been subjected to the compression of the rubber rings, yields blood which shows a progressive rise in the percentages of the corpuscles and of the hremoglobin until an hour has elapsed, when the increment amounts to from 8 to ro per cent.; then the percentages gradually fall, arterial pressure. It may, I think, be inferred from these facts that the capillary blood pressure follows the same curve after meals, for we know that this pressure is more closely related to the venous than to the arterial, and that

1 Abstract of the Oliver-Sharpey Lectures on Recent Studies on the Tissue-lymph Circulation, by Dr. George Oliver. Nelivered before the Royal College of Physicians of London on April I2 and 14.

2 Proceeaings of the Royal Society, June $1 \mathrm{I}$, 1903; The Lancet. October 3,1903, p. 940 ; and the Journal of the British Balneological and Climatological Society, I903.

NO. I804, VOL. 70]
1065

1064

1063

1062

1061

1060

1059

1058

1057 Fig. 2.- Chart showing the percentages of corpuscles and the specific gravity of the blood before
and after compression. Observations made before a meal and at frequent intervals afterwards.

and they finally settle down to normal in from two and a half to three and a half hours (Fig. 2, A). Should, however, the blood be derived from the finger in the ordinary way (without compression), the successive readings of the blood elements indicate a progressive fall in the percentages, which in an hour amounts to from 6 to 8 per cent., when a rise sets in and recovery is eventually established (Fig. 2, B)

Digestive variations in the specific gravity of the blood.The blood, as shown by compression of the finger, rises in 
specific gravity after meals, the rise reaching its maximum point (e.g. from $106 \mathrm{I}$ to 1065$)$ in an hour. The specific gravity then begins to fall, settling down to the initial point at the conclusion of the wave-like disturbance (Fig. 2, A). On the other hand, the blood derived from the finger uncompressed affords a specific gravity which follows the contrary course, that is to say, it falls and then rises (Fig. 2, B). When the digestive disturbance is over, the variations in the blood, like those in the circulation, cease, and the readings in normal subjects at rest continue to be alike in both samples (before and after compression) until the following meal.

The digestive exudation of tissue lymph.-On reviewing the foregoing data it is obvious that they indicate strictly concurrent events. All the four series of variations follow exactly the same curve. What is the link which binds them together? If we suppose that the ingestion of food in some way raises the capillary blood pressure which exudes a filtrate of a portion of the liquor sanguinis into the areolar spaces, all the changes in the blood which $I$ have described will naturally follow (see Fig. 2). In proportion to the exudation under a rising capillary blood pressure, the blood will become more and more concentrated in chromocytes and in hæmoglobin, and inasmuch as its specific gravity mainly depends on the corpuscles, the density of the blood will rise pari passu with the increased concentration. Then, when the capillary pressure begins to fall, as it does after the acme of the digestive disturbance has been attained, the concentration of the blood diminishes, and we may assume that either absorption of the watery elements of the effused lymph overbalances exudation or that the effusion is being returned by the lymphatics to the blood. Now I have shown that none of these alterations in the blood could have been ascertained by the examination of blood derived from the finger in the ordinary way; they only become apparent after the compression of the tissues by the rubber rings, which removes the extra-capillary fluid and enable us to obtain the blood undiluted by that fluid. But the progressive readings of the ordinary samples of blood, though valueless, and actually misleading when accepted as independent testimony of blood changes during digestion, become instructive when compared with the readings of samples obtained after compression, for they then afford a measure of the amount of fluid withdrawn from the blood. The differential readings of the hæmocytometer tubes made every fifteen minutes after a meal show the greatest divergence, and therefore the largest quantity of tissue fluid, just at the time (an hour after a meal) when the digestive blood pressure wave and the concentration of the blood attain their maximum development. The difference, indicated by the scale on the tubes, will amount to from 15 to 20 per cent.; it will then gradually diminish, and will finally disappear in from two and a half to three and a half hours, and will not reappear until after the next meal or until exercise is taken. The amplitude and duration of the lymph wave are influenced by various conditions, such as the tone of the subject, the bulk and nature of the meal, the use of beverages, rest, or exercise.

Other rhythmical digestive variations.--I will now direct your attention to other physiological variations produced by the ingestion of food, synchronous with the foregoing. These are:-(I) the digestive curve of augmented respiratory exchange determined by Fredericq and other observers; (2) the gastric juice curve of Pawlow; and (3) a digestive rhythmical variation of muscular contractility, which came to light while studying the effects of muscular tension on the arterial pressure. It was found that when tissue-lymph was not apparent (e.g. before meals), the tension raised the arterial pressure to a maximum degree (e.g. $40 \mathrm{~mm}$.), whereas when the lymph was fully effused (an hour after a meal) the pressure could only be slightly raised (5 or ro $\mathrm{mm}$.). The digestive curve of muscular contractibility (i.e. the capability of being contracted) is therefore the reverse of the lymph curve, and it is inferred that the exudation of the lymph into the muscular tissue checks the shortening of the muscular fibres, and thus diminishes the effect of their contraction on the intramuscular vessels.

These observations on the condition of the muscles during digestion, therefore, confirm the teaching as to the outflow and absorption of lymph furnished by the differential ex- amination of the blood. At the termination of the digestive disturbance there is apparent a gain in the contractile energy, as expressed in an additional rise of the arterial pressure produced by muscular tension. This gain (which only becomes evident after the absorption of the lymph) varies from 5 to 20 millimetres, according to the nature of the food consumed and the need for recuperation.

The effects of typical meals on the digestive lymph flow. Let us now study the digestive curves of lymph exudation produced by four different kinds of meals. First, the ordinary mixed meal containing the usual proportions of animal food, vegetables, and farinacea; secondly, the meat meal, consisting of animal food in various forms, with cheese and butter and a very little toast; thirdly, the vegetable meal, with farinaceous puddings, fruit, and cheese ; and fourthly, the milk meal, milk, bread, and farinaceous puddings. In each case the fluid supplied was a tumbler of water, and the amount of food was merely limited by a feeling of satisfaction. Sugar and salt (two grams of each) were taken in the same quantity at all the solid meals. The meal was at one o'clock, and the same subject was throughout submitted to observation. No exercise was permitted for an hour before and after meals, nor until the digestive disturbance had quite subsided. Observations were made just before the meals and every fifteen minutes after them. The results are epitomised in the following table (Table I.) :-

TABLE I.

\begin{tabular}{ccccccccc} 
The meal & & & \multicolumn{3}{c}{$\begin{array}{c}\text { Maximum } \\
\text { per cent. }\end{array}$} & \multicolumn{3}{c}{$\begin{array}{c}\text { Duration } \\
\text { hours }\end{array}$} \\
Roast meat & $\ldots$ & $\ldots$ & $\ldots$ & $30 \cdot 0$ & $\ldots$ & $\ldots$ & 5 \\
Mixed $\ldots$ & $\ldots$ & $\ldots$ & $\ldots$ & $17 \cdot 5$ & $\ldots$ & $\ldots$ & 3 \\
Vegetable & $\ldots$ & $\ldots$ & $\ldots$ & $12 \cdot 5$ & $\ldots$ & $\ldots$ & 3 \\
Milk $\ldots$ & $\ldots$ & $\ldots$ & $\ldots$ & 7.5 & $\ldots$ & $\ldots$ & I $\frac{1}{2}$
\end{tabular}

You see that the lymph curves produced by these several kinds of meals vary enormously in amplitude and length, and in the following descending order :-meat meal ordinary meal, vegetable meal, and milk meal. The net gain in muscle contractility shown by the tension test after the subsidence of the digestive disturbance and the removal of the lymph is in the same order, expressed by the following figures :- 15 (meat meal), ro (ordinary meal), 7 (vegetable meal), and 3 (milk meal). Some light will be thrown on these results by studying the effect of the separate food elements.

The effect of the food elements on the production of tissue lymph.-I will first mention those substances which, according to my observation, do not alter the blood pressure or cause the flow of tissue lymph:-cold water, starch, fats, gelatin, proteid as represented by myosin or egg-albumin, the sugars (cane sugar, glucose, maltose, galactose, mannose, dextrose, and inulin), pepsin, and hydrochloric acid. Cold water (e.g. 500 cubic centimetres, or a little more than $\mathrm{r} 6$ ounces) has no effect, but the same amount of warm water lowers the arterial pressure. This is therefore a temperature effect. In regard to proteids, I selected chemically pure myosin (muscle proteid) and white of egg as representative of the group. So far their effects have been negative. In support of this conclusion we have also the fact that the lymph exudation produced by a meal of roast beef is 30 per cent., whereas that caused by a meal of boiled meat is only 7 per cent. All the sugars named also produce negative results. There are, however, other sugars (glycogen, lævulose, and lichenin) which have been found decisively to affect the blood pressure and the flow of lymph.

Inorganic salts.-I will here only refer to sodium and potassium chlorides, as my observations on the effects of other salts are not sufficiently advanced for publication. Sodium chloride, in percentages varying from $\mathrm{I} \cdot 5$ to $2 \cdot 0$, invariably raises the arterial pressure and increases the outflow of tissue $1 \mathrm{ymph}$; four grams produce in thirty minutes the exudation of 15 per cent. lymph, which is completely absorbed in thirty minutes more. Potassium chloride lowers the arterial pressure, four grams producing a fall of from to to 12 millimetres of mercury. Sodium chloride increases and potassium chloride diminishes the digestive curves. When these two salts are taken in equal proportions-e.g. two grams of each-their effects on the blood pressure and lymph flow neutralise each other. 
Muscle extractives. -The lymph exudation produced by home-made beef-tea, derived from half a pound of beef infused first in cold water and then in hot, is similar in amplitude to that of a meat meal (see supra), onily it is of shorter duration. Two well known beef extracts, selected out of several as typical of the rest, gave a somewhat smaller amount of lymph exudation, the quantities taken being those directed by their proprietors. No salt or other seasoning was added to the preparations. The following products derived from muscles have been administered, dissolved or suspended in six ounces of cold water:-creatin, creatinin, xanthin, hypoxanthin, uric acid, carnin, and glycogen.

[Dr. Oliver here described how the matter of dosage was settled.]

The doses thus worked out may seem to the experimental physiologist to be absurdly small, but the uniform results obtained in different subjects showed that it was not necessary to experiment with larger quantities. My observations show that uric acid (either as uric acid or as ammonium urate), xanthin, creatinin, carnin, and glycogen produce a decided rise in the blood pressures (arterial, capillary, and venous) and increase the exudation of tissue lymph, the pressure and the exudation rise being proportionate to each other. This effect from ingesting glycogen was quite unexpected. The accompanying table gives the doses, the maximum lymph exudation and arterial pressure, and the duration of these effects.

TABLE II.

\begin{tabular}{|c|c|c|c|c|c|}
\hline & $\mathrm{Ma}$ & $\mathrm{m}$ & $n$ rise & & \\
\hline & $\begin{array}{l}\text { Lymph } \\
\text { per cént. }\end{array}$ & & $\begin{array}{l}\text { Arterial } \\
\text { pressure } \\
\text { mm. } \mathrm{Hg}\end{array}$ & & $\begin{array}{l}\text { Duration } \\
\text { effect in } \\
\text { minutes }\end{array}$ \\
\hline $\begin{array}{l}\text { Carnin, } \\
\left(\frac{1}{2} \text { grain }\right) \\
\end{array}$ & 15 & $\ldots$ & 115 & & \\
\hline $\begin{array}{c}\text { Creatinin, gram } \\
\left(\frac{1}{2} \text { grain }\right)\end{array}$ & & & & $\cdots$ & 30 \\
\hline $\begin{array}{ccc}\text { Glycogen, gram } & 0.0325 \\
\left(\frac{1}{2} \text { grain }\right) \ldots & \ldots & \ldots\end{array}$ & 14 & $\cdots$ & 114 & $\cdots$ & 30 \\
\hline Ditto, gram 0.13 & & $\cdots$ & & $\cdots$ & 23 \\
\hline 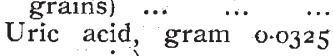 & 20 & $\cdots$ & 120 & $\ldots$ & 90 \\
\hline $\begin{array}{ll}\text { grain)... } & \ldots \\
\text { Ammonium } & \text { urat } e,\end{array}$ & I7 & $\ldots$ & II 7 & $\ldots$ & 85 \\
\hline $\begin{array}{l}\text { gram } 0.13 \text { (2 grains) ... } \\
\text { Xanthin, gram } 0.0325\end{array}$ & 25 & $\ldots$ & 125 & $\ldots$ & rIo \\
\hline$\ldots$ & 20 & $\ldots$ & 120 & $\ldots$ & 105 \\
\hline
\end{tabular}

A long latent interval (about twenty minutes) elapsed after swallowing uric acid or ammonium urate and xanthin before any effect on the blood pressure was apparent, a fact which may be accounted for by the low solubility of these products, which, however, produced effects more decided and more prolonged than those which followed the other products. Creatin and hypoxanthin differ from the other allied products in their effects on the arterial pressure. Creatin produces at first a fall which is followed by a rise, and hypoxanthin causes a marked fall in the arterial and an equally decided rise in the venous pressure.

When xanthin is combined with it in equal parts, the blood pressures remain unattered. In like manner when creatinin is taken with creatin (equal parts) the preliminary fall of arterial pressure produced by creatin fails to appear, and the effects of the two agents balance each other for twenty minutes, after which the rise of creatinin combined with the ultimate rise of creatin take their normal course. All the muscle-derived products raise the capillary blood pressure, increase the exudation of tissue lymph, and are cardiac stimulants.

The active principles contained in beverages.-Allied to most of the foregoing products in their chemical constitution and physiological action on the blood pressure and lymph circulation are the active principles of tea, coffee, and cocoa, caffein and theobromin being methylxanthins, the former being called tri- and the latter di-methylxanthin. They are therefore bodies with a purin basis $\left(\mathrm{C}_{5} \mathrm{~N}_{4}\right)$, and, like most of the other purin bodies, they raise the blood pressure in a long, well sistained curve, with an accompanying wave-like exudation of tissue $1 \mathrm{ymph}$, and they are also like the other purins in being cardio-stimulants.

The effects of alcohol on the blood pressure and lymph NO. I804, vOL. 70] circulation are modified very considerably by the presence of other constituents in spirits, wines, malt liquors, \&c. The arterial pressure curve of absolute alcohol at first falls and then rises, the fall below the normal being equivalent to the rise above it. It therefore resembles that of creatin, and differs from that of xanthin, uric acid, creatinin, and glycogen.

Whisky follows the compound curve of absolute alcohol; brandy, wines, and beer conform to the simple curve of the bodies just mentioned, and gin follows the curve of hypo-

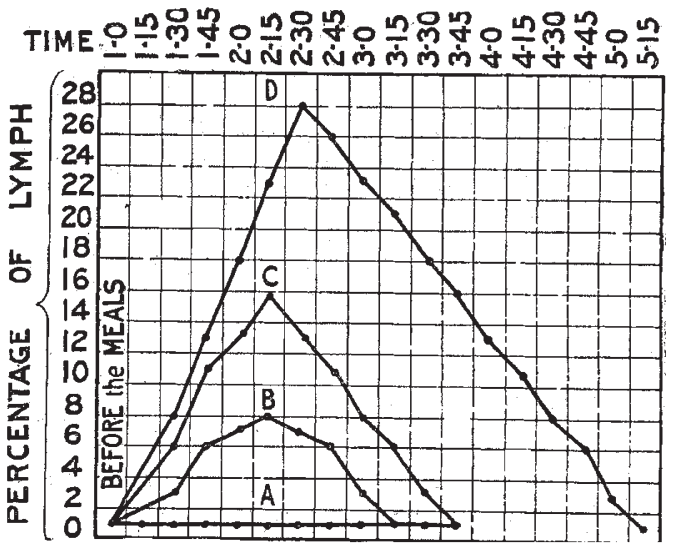

Frg. 3.-A, lymph record from purin-free meal, B, purin-free meal with sodium chloride 2'o grams. C, purin-free meal with sodium chloride $4^{\circ} \circ$ grams. D, purin-free meal with sodium chloride 2 grams and uric acid $0^{\circ} \circ 16$, creatin $0^{\circ} 033$, creatinin $0^{\circ} 033$, xanthin $0^{\circ} \circ 6$, hypo. xanthin c'or6, and glycogen 0 ' 048 .

xanthin, - this marked difference being due to the juniper it contains.

I conclude from the foregoing data that caffein, theobromin, and the alcoholic beverages (but more especially brandy, wines, and malt liquors) excite the flow of tissue lymph like the purin and the other products previously mentioned.

\section{How is the Digestive Exudation of Tissue Lymph} PRODUCED?

We are led by the foregoing data to the following conclusions:-(I) That the food constituents themselves (proteids, fats, and carbohydrates) do not possess the power of starting the mechanism by which $1 \mathrm{ymph}$ is dispensed to the tissues throughout the body. (2) That nature, however, associates with our food-stuffs small quantities of certain very active substances which bring into play that mechanism, though these substances themselves are practically devoid of food value; and that man frequently increases this natural lymph stimulation by the use of salt and beverages containing bodies which also incite the flow of $1 \mathrm{ymph}$.

But let us put this matter to the test of experiment. It is possible to arrange a meal containing a fairly large quantity of nutrient elements in such a way that it will not react on the circulation at all, and will not induce the flow of tissue lymph. Such a meal consists of three or more eggs, a full supply of white bread, boiled rice or tapioca, cream, sugar, and cheese, with a tumbler of cold water. I have taken this meal several times with the feeling of repletion, and yet it has not produced a rise of blood pressure or the slightest flow of tissue lymph.

In Fig. 3 a shows the negative effect of this meal on the tissue $1 \mathrm{ymph} ; \mathrm{B}$ and $\mathrm{c}$ indicate two exudations produced by adding two and four grams of sodium chloride to the meal; and $\mathrm{D}$ is a voluminous lymph wave resulting from the addition of a mixture of the following products with two grams of salt:-uric acid, 0.016 gram; creatin, 0.033 gram; $\cdots$ creatinin, 0.033 gram; xanthin, 0.016 gram hypoxanthin, o.or6 gram; and glycogen, 0.048 gram. The meal produced a much more refreshing and sustaining effect when the digestive lymph flow was excited by the addition of salt, and more especially by that of salt associated with the physiological products than when taken alone. 


\section{EXERCISE.}

The fundamental effects of exercise on the blood pressure may be readily studied in an epitomised form by placing the pad of the hæmodynamometer over a small superficial artery, like the superficialis volæ, and then throwing all the muscles into a state of tension for sixty seconds (the arm on which the observation is made being excluded from the contraction). In Fig. 4 you observe that the complete arterial pressure curve of muscular contraction is made up of two elevations, (A) primary and (C) secondary, separated by a fall (B) which is just as decidedly below the normal pressure as the second rise is above it. The first elevation (A) is synchronous with the tension, and the second (C) appears after the muscles are relaxed.

Now these oscillations of the arterial pressure are all seen on a larger scale in ordinary exercise, each stage being, of course, prolonged in proportion to the duration of the exercise. The primary rise is invariably followed by a gradual fall, even during the continuance of the exercise, and by a rapid and decisive fall on its cessation, and that fall is succeeded during rest by a second rise.

Sir Lauder Brunton and Dr. Tunnicliffe are, I believe,

will fall, and lymph will not be exuded. But the state of the circulation is different in the non-muscular parts, for all the blood pressures (arterial, capillary, and venous) are markedly raised during the sustained tension of the muscles. Hence the effusion of lymph in the finger. On the other hand, when the contraction ceases, the intra-muscular capillary pressure will rise, and lymph will then be effused into the muscles. That the muscles when relaxed after contraction become full of blood is shown by the work of Ludwig and his pupils, and by Sir Lauder Brunton and Dr. Tunnicliffe, who have furnished graphic evidence of the dilatation of the intra-muscular arteries which follows contraction ( $o \dot{p}$. cit.).

As after food so after exercise the contractibility of the muscles (as indicated by the tension test) diminishes in proportion to the amount of lymph effused.

Exercise likewise provides us with some instructive facts as to how tissue-fluid is removed. Observation has shown that a short muscular contraction of sixty seconds will produce two effusions, one during the contraction which is entirely absorbed in sixty seconds, and another which is immediately afterwards thrown out, and disappears just as quickly, so that in four minutes we have two successive effusions which entirely clear up. The rapidity with which lymph disappears from the tissues in a state of rest certainly favours the notion of absorption rather than that of transmission along the lymphatics. Now, experimentation on animals has shown that muscular action of some kind is necessary to ensure a flow of lymph along the lymphatics, so we may conclude that during exercise the muscular action will more particularly favour that passage for the $1 \mathrm{ymph}$.

\section{FATIGUE}

Observation has shown that the rise in the arterial pressure produced during the continuance of exercise becomes less and less pronounced in proportion to the duration of the exercise; for example, the initial increase of from 15 to $20 \mathrm{~mm}$. gradually subsides until after the lapse of a certain time (which varies with the tone of the individual and with the external temperature), the arterial pressure will not exceed roo mm. $\mathrm{Hg}$; and if the exercise is further continued it will even fall lower, to 95. 90 , or $85 \mathrm{~mm}$. This point was also observed by Sir Lauder Brunton and Dr. Tunnicliffe.

Why should the rise of pressure, normally induced by exercise, be effaced or even replaced by a fall when exercise is prolonged?

Inasmuch as the lymph exuded during exercise obstructs the contractile pressure of the muscular fibres on the intra-muscular arteries and arterioles, the peripheral resist-

Fig. 4.-The effect of muscular tension on the arterial pressure; (A) rise from muscular tension; (B) fall on relaxing the muscles; (C) secondary rise during rest.

the only observers who have furnished trustworthy data on the blood pressure in man, both during muscular movement and immediately after its cessation, and their data accord with my own. ${ }^{1}$

The secondary rise of blood pressure which I have invariably found to supervene during rest after exercise does not, however, seem to have been recognised by other observers.

Exercise invariably increases the exudation of tissuelymph. Inasmuch as it is rapidly absorbed on the cessation of exercise, the observation must be made without delay.

How are these effects of exercise produced? According to Ludwig and Gaskell (Ludwig's "Arbeiter," .I877), during a short tetanus the flow from the efferent vein of the muscle, after the first spurt of blood, may fall to practically nil. Therefore we may infer that muscular contraction causes partial or temporary occlusion of the intra-muscular vessels, and that this increase of peripheral resistance, along with reflex cardiac stimulation, will go far to explain the rise in the arterial pressure.

At the same time, the capillary pressure within the muscle

1 "Remarks on the Effect of Resistance Exercises upon the Circulation in Man, Local and General," by Sir Lauder Brunton and F. W. Tunnicliffe, M.D. (Brit. Med. Journ., October 16, 1897.)

No. I 804 , VOL. 70] ance caused by exercise will be reduced, and the arterial pressure will gradually fall. In fatigue, no amount of will exerted over the muscles can raise the arterial pressure at all; the muscles, though capable of ordinary contraction, become, as it were, lymph-logged. But massage quickly disperses the $1 \mathrm{ymph}$, and the contractibility is restored. Human instinct, without knowing the "why," practised what is now taught by physiological inquiry. We read in the "Odyssey " how the women rubbed and kneaded their weary heroes returned from battle, and thus invigorated them, and we know that from time immemorial rubbing was the sovereign remedy for fatigue.

The physiology of fatigue includes another important factor, namely, diminished gravity control over the blood pressure. The outcome of exercise is the production of hypotonia in the vaso-motor mechanism, which is the central fact, as it were, of fatigue.

REST.

During rest after exercise there is developed a steady and persistent rise of the blood pressures and a corresponding effusion of $1 \mathrm{ymph}$, and the volume and duration of this second outflow of $1 \mathrm{ymph}$ are always proportionate to the vaso-dilator or reducing effect of exercise. The physiological intent of it is to repair and recharge the muscles, 
for after the lymph is absorbed the contractibility is always found to be restored. How are the muscles thus automatically renovated without food? It seems highly probable that the reparative lymph exudation which follows exercise is produced by the agency of chemical substances generated by muscular contraction, just as the digestive lymph flow is caused by exogenous lymphagogues. Creatin and lactate of ammonium produce the double curve of arterial pressure induced by exercise and rest.

\section{SLeEp.}

A large volume of lymph (not less than 20 per cent.) is exuded into the somatic tissues during sleep.

In sleep the arterial pressure falls very low (from 78 to $82 \mathrm{~mm} . \mathrm{Hg})$ and the venous pressure rises to a high point (40 to $50 \mathrm{~mm}$. $\mathrm{Hg}$ ). There is complete physiological vasomotor relaxation, consequently the veins not only of the somatic, but of the splanchnic area are filled with blood. The splanchnic stasis is shown by the fact that when a weight (a shot bag of $14 \mathrm{lb}$.) is applied to the abdomen, the arterial pressure is raised at once from 80 to $100 \mathrm{~mm}$. $11 \mathrm{~g}$. In a few minutes, however, when the subject is fully awake, the arterial pressure rises to $95 \mathrm{~mm}$. $\mathrm{Hg}$ or so, the venous pressure falls to 15 or $20 \mathrm{~mm}$. $\mathrm{Hg}$, the shot bag no longer raises the arterial pressure, and the effused lymph of sleep, having become absorbed, is no longer apparent.

What is nature's intent in thus supplying the tissues so liberally with lymph during our sleeping hours? The answer admits of no doubt-restoration; and how true to fact is the old proverb, "He who sleeps, dines"! For during sleep nature provides the maximum amount of tissue-lymph, which we only obtain intermittently after meals. Can this be proved? The answer is provided by the tension test.

[Dr. Oliver here epitomised the results of a night and morning record, demonstrating in figures the restorative power of sleep.]

[The effects of gases (oxygen, carbonic acid, sulphurous acid, sulphuretted hydrogen, and the atmosphere of sewers), of gravitation, of temperature, and of internal secretion (supra-renal, thyroid) on the tissue-lymph circulation were rescribed, and the vexed question as to whether tissue-lymph is a secretion or a pressure product was discussed.]

Is there an intermediary circulation?-The rapid removal of lymph from the tissues when the muscles are at rest, for example, after exercise and on awaking from sleep, suggests absorption rather than transmission by the lymphatics. Therefore I think there is evidence in support of a circulation of fluid independent of the lymphatic circulation, though controlled by the capillary circulation, of which it may be said to be an extension.

There is not time to discuss the forces involved. The best account of them, as at present known, is that given by Prof. Starling, of University College, than whom no one has done more valuable work in support of Ludwig's pressure theory (Schäfer's " Text-book of Physiology, vol. i.). Ludwig pointed out that the prime factors in the effusion of lymph are filtration and diffusion. My observations refer only to filtration, and they suggest such a scheme of the intermediary circulation as is represented in Fig. 5, which shows the mechanism, as it were, for the supply of pabulum to the tissues (AA) and for the removal of soluble waste from them (BB). The view there represented explains why the ingestion of food restores the tissues at once, and long before the food itself can be assimilated into the blood. The exhausted tissues have not, therefore, to remain unsupplied until the food becomes part of the common store of pabulum, which the blood keeps ready for distribution. Each supply of food may be viewed as a deposit paid to our banking account, but it is not merely a deposit, for nature combines

Nu. 1804 , VOL. TO] with it a cheque for payment; the banker therefore is compelled to reimburse at the same time that he receives, so that the balance is kept fairly uniform.

In normal subjects each effusion of tissue-lymph is intermittent, rising out of and subsiding into an apparently lymph-free state of the tissues when the capillary bloodpressure (as indicated by the venous pressure) touches its minimum point. Probably at such times some trace of tissue fluid is actually present, but insufficient to be made apparent by the ordinary use of the differential test.

[Some practical deductions were here drawn, and new remedies suggested by the inquiry were described.]

There is much more work to be done, but meanwhile let me summarise a few provisional conclusions:-

(I) Tissue-lymph is intermittently effused, for example, after the ingestion of food, during exercise, rest after exercise, and during sleep.

(2) The rapid effusion and removal of it in states of rest suggest the existence of a circulation between the blood

\section{$3 \frac{1}{2}$ HOURS ( of BLOOD}

1065

1064

1063

1062

1061

1060

1059

1058

1057 of tissue fluid containing soluble waste and salts.

and the tissue spaces-a circulation independent of the lymphatic circulation.

(3) The apparent physiological intent of the effusion is reparative, and that of its absorption to aid the removal of tissue waste.

(4) By studying the conditions which increase or decrease lymph effusion, we ought to gain a clearer insight as to how to control derangements of nutrition and metabolism.

\section{UNIVERSITY AND EDUCATIONAL INTELLIGENCE.}

Mr. Hubert M. Turnbull, Magdalen College, Oxford, has been elected to a Radcliffe travelling fellowship for three years.

The Rede lecture at Cambridge will be delivered on June I I by Dr. J. A. Ewing, F.R.S., upon "The Structure of Metals."

DR. F. G. Donnan, lecturer in chemistry in the Royal College of Science, Dublin, has been elected to the chair of physical chemistry recently founded by Sir John T. Brunner in the University of Liverpool.

THE British Medical Journal states that the new medical laboratory of the University of Pennsylvania is to be opened on June 30. Exclusive of site and equipment, the building has cost nearly 140,000 . It is the first of a group of buildings it is proposed to erect, which when completed will, it is hoped, form the largest system of buildings devoted to the teaching of medicine in the world.

As a general result of the various movements in recent years to establish a centre of veterinary education in Liverpool, it has been arranged, we learn from the Times, that Prof. Williams, of the New Veterinary College, Edinburgh, shall transfer his teaching centre to Liverpool and take up the professorship of veterinary medicine and surgery offered by the Institute of Comparative Pathology, and shall act as principal or dean of the veterinary school. Prof. Williams will be placed upon the same footing as professors in the university, and the cost of the professorship has been privately guaranteed for a period of years. In accordance with a scheme drawn up five years ago by 